\title{
Air pollution perception in ten countries during the COVID-19 pandemic
}

\author{
Baowen Lou (1), Diego Maria Barbieri (1), Marco Passavanti (1),

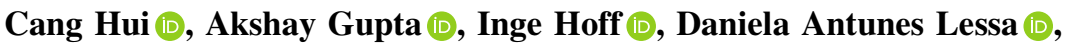 \\ Gaurav Sikka (1), Kevin Chang $\mathbb{1}$, Kevin Fang $\mathbb{1}$, Louisa Lam $(\mathbb{D}$,

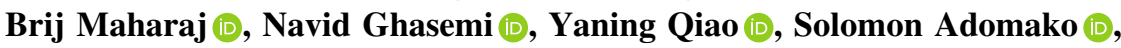 \\ Ali Foroutan Mirhosseini (1), Bhaven Naik $(\mathbb{D}$, Arunabha Banerjee $(\mathbb{C}$,

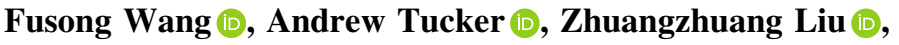 \\ Kasun Wijayaratna (10, Sahra Naseri (iD, Lei Yu (1), \\ Hao Chen (1), Benan Shu (1), Shubham Goswami (D), Prince Peprah (1), \\ Amir Hessami $\mathbb{B}$, Montasir Abbas $\mathbb{B}$, Nithin Agarwal $\mathbb{1}$
}

Received: 23 October 2020/Revised: 17 January 2021 / Accepted: 9 May 2021/Published online: 21 June 2021

\begin{abstract}
As largely documented in the literature, the stark restrictions enforced worldwide in 2020 to curb the COVID-19 pandemic also curtailed the production of air pollutants to some extent. This study investigates the perception of the air pollution as assessed by individuals located in ten countries: Australia, Brazil, China, Ghana, India, Iran, Italy, Norway, South Africa and the USA. The perceptions towards air quality were evaluated by employing an online survey administered in May 2020. Participants $(N=9394)$ in the ten countries expressed their opinions according to a Likert-scale response. A reduction in pollutant concentration was clearly perceived, albeit to a different extent, by all populations. The survey participants located in India and Italy perceived the largest drop in the air pollution concentration; conversely, the smallest variation was perceived among Chinese and Norwegian respondents. Among all the demographic indicators considered, only gender proved to be statistically significant.
\end{abstract}

Keywords Air quality - COVID-19 pandemic . Environmental pollution · Pollution perception . Psychometric perception

Supplementary Information The online version contains supplementary material available at https://doi.org/10.1007/s13280021-01574-2.

\section{INTRODUCTION}

\section{Background}

Air pollution is a global environmental issue, which has been steadily increasing during the last decades due to urban sprawl and anthropogenic activities (Yang et al. 2018; Li et al. 2019a) causing severe health diseases (Lelieveld et al. 2015; Cohen et al. 2017; Burnett et al. 2018) and reducing people's Subjective Well-Being (SWB) to a significant degree ( $\mathrm{Li}$ et al. 2018). On average, approximately 4 million deaths per year can be linked to poor air quality and pollutants (i.e. particulate matter PM, which is usually referred to according to an aerodynamic diameter of less than $2.5 \mu \mathrm{m} \mathrm{PM}_{2.5}$ or $10 \mu \mathrm{m} \mathrm{PM}_{10}$, ozone $\mathrm{O}_{3}$, nitrogen oxides $\mathrm{NO}_{\mathrm{x}}$, carbon monoxide $\mathrm{CO}$ and sulphur dioxide $\mathrm{SO}_{2}$ ), especially in major developing countries (WHO 2016).

Facilitated by globalisation and our hypermobile society (Acter et al. 2020; SanJuan-Reyaes et al. 2020; Sarkar et al. 2020), the COVID-19 pandemic has become another grave issue for humanity as a whole, forcing radical changes in many social, economic and hygienic behaviours (WHO 2020a, b; Passavanti et al. 2021; Wu 2021). In order to curb the spread of the COVID-19 virus, a significant amount of the global population has been requested to comply with restrictions to economic and mobility activities (De Vos 2020; Wilder-Smith and Freedman 2020; Barbieri et al. 2021). Although essential industries have been operating continuously (Wang et al. 2020a b), the massive decline in the global pattern of energy demand (i.e. crude oil and 
coal) and the general slowdown of anthropogenic activities have involuntarily imposed a unique scenario curtailing detrimental emissions released into the troposphere (Berman and Ebisu 2020; Kumari and Toshniwal 2020; Shi and Brasseur 2020) offering "the nature a healing time" (Lokhandwala and Gautam 2020).

Unlike other sudden large-scale drops in air pollution recorded previously in relation to particular events ( $\mathrm{Li}$ et al. 2019b), such as the 1996 Atlanta Olympics (Friedman et al. 2001), the 2008 Beijing Olympics (Huang et al. 2012) and the 2014 Asia-Pacific Economic Cooperation meeting (Wang et al. 2017), the geographical extent of the effects exerted by the COVID-19 pandemic has been global. In this regard, there are numerous studies, which performed robust chemical and meteorological analyses, documenting the reduction in air pollution during the pandemic for a variety of noxious particles and gases, i.e. particulate matter $\mathrm{PM}_{2.5}$ (Chauhan and Singh 2020; Rodríguez-Urrego and Rodríguez-Urrego 2020), nitrogen dioxide $\mathrm{NO}_{2}$ (ESA 2020; NASA 2020a b c; Venter et al. 2020; Liu et al. 2021), carbon monoxide CO (Dantas et al. 2020; Barua and Nath 2021) and carbon dioxide $\mathrm{CO}_{2}$ (Le Quéré et al. 2020; Andreoni 2021) and a moderate decrease in Aerosol Optical Depth (Lal et al. 2020; Muhammad et al. 2020).

\section{Scope of the study}

Unique to the number of existing studies focussing primarily on measured environmental implications of the pandemic-related restrictions (Shakil et al. 2020), this research addresses a topic that has been often neglected, namely assessing the human perceptions towards air quality and its change. In particular, we investigate the perceptions related to air pollution experienced by individuals located in ten countries: Australia, Brazil, China, Ghana, India, Iran, Italy, Norway, South Africa and the USA (hereafter, also referred to by their acronyms AU, BR, $\mathrm{CH}, \mathrm{GH}, \mathrm{IN}, \mathrm{IR}, \mathrm{IT}, \mathrm{NO}, \mathrm{ZA}$ and USA, respectively).

Following previous psychometric investigations dealing with perceptions of air quality (Nikolopoulou et al. 2011; Pu et al. 2019; Reames and Bravo 2019) and psychological impacts on people's Subjective Well-Being (Li et al. 2018) by means of opinion surveys, this study captures the perceptions towards atmospheric quality related to before and during the enactment of the pandemic-related restrictions (Barbieri et al. 2020b).

Previous psychometric researches highlighted that several factors, ranging from social, personal, political to cultural dimensions, can affect the air quality perception. At the same time, the information regarding environmental pollution conveyed to the general public may not always result transparent because of issues related to information source (i.e. biased coverage) or information receiver (i.e. difficulty in understanding highly technical content). Compounding this, it is unclear the extent according to which information and awareness about air pollution can effect actual behavioural changes (Oltra and Sala 2014). We employed an online survey administered in the abovementioned ten countries in May 2020. This approach allows for a comparison, at a cross-country scale, of how air quality has been perceived by residents with various demographics facing different levels of air pollution before the COVID-19 pandemic.

The detrimental health effects related to the exposure to particulate matter PM (Puett et al. 2009; Hoek et al. 2013; Hamra et al. 2014; Stafoggia et al. 2014) and ozone $\mathrm{O}_{3}$ ( Ito et al. 2005; Nuvolone et al. 2018; Feng et al. 2019; Siciliano et al. 2020b) are largely believed to be the most hazardous form of air pollution (WHO 2006). Therefore, considering the relevance of $\mathrm{PM}_{2.5}, \mathrm{PM}_{10}, \mathrm{O}_{3}$ for both physical and psychological well-being (Rotko et al. 2002; $\mathrm{Li}$ et al. 2018), we investigate the level of variations in the pollutants concentration that are likely to trigger perceptual changes.

\section{MATERIALS AND METHODS}

\section{Research on air pollution perception}

The earliest studies encompassing people's perceptions on air pollution were performed in the 1960s and were largely quantitative and evaluated the extent of public awareness on diverse environmental issues (Smith et al. 1964; Schusky 1966; de Groot 1967; Crowe 1968). As the perception of air pollution represents a multifaceted topic, starting from the 1990s a new body of research started to adopt qualitative methods in two areas: (i) understanding the demographic, social and cultural determinants related to the interpretation and the perception of air pollution (Bickerstaff and Walker 1999; Bush et al. 2001a b) and (ii) enhancing communication in a reliable and trustworthy fashion to stimulate public behavioural changes (Beaumont et al. 1999; Howel et al. 2003).

The general improvement in air pollution during the COVID-19 pandemic has received wide coverage in the news and other journalistic platforms, thus inspiring growing discussions among the general public on social media and websites (Brimblecombe and Lai 2020; CasadoAranda et al. 2020; Alshaabi et al. 2021). This phenomenon is in line with previous large-scale events which stimulated the rise of environmentalism in different locations across the globe (Brimblecombe and Zong 2019). The psychological effects of air pollution (i.e. anxiety, depression, distress, nuisance, impairments in concentration), generally less investigated than the physical effects, are a crucial 
factor to successful environmental policies for addressing pollution abatement (Deguen et al. 2012); in addition, few studies have involved developing countries (Saksena 2011). In general, females of all age classes living in urban areas and with higher education represent the part of the population most concerned about environmental issues (Oltra and Sala 2014). Nevertheless, the lack of awareness about the sources of pollution and its consequences is present across various socio-economic groups and often entails underestimation of objective reality (Oltra and Sala 2014; Maione et al. 2021).

\section{Survey investigation}

An online survey was developed and administered to evaluate the public perceptions of the quality of air before and during the COVID-19 restrictions enforced in each of the ten countries (Australia, Brazil, China, Ghana, India, Iran, Italy, Norway, South Africa and the USA) allowing for a cross-sectional study. Respondents expressed their opinions according to a 7-point Likert-scale question with "1 = extremely low/absent air pollution" and "7 = extremely high air pollution". The questionnaire also collected information regarding gender, age and education of the participants (Barbieri et al. 2020b).

The web-based survey in this study was created with Google Forms and WenJuanXing (translated into Chinese, English, Italian, Norwegian, Persian, Portuguese) and distributed between the 11th and the 31st of May 2020 by means of professional and social networks (including but not limited to email lists, Facebook, LinkedIn, Twitter, Instagram, Skype, WhatsApp, WeChat, Weibo, QQ and Douban) using purposive sampling technique (De Beuckelaer and Lievens 2009; Stockemer 2019); more respondents were obtained via snowball sampling through the forwarding and sharing the survey by initial recipients. The linguistic validity across the ten countries was pursued following a translation-back-translation approach (Brislin 1976): after translating the survey into local languages, the survey was back translated. The research team carefully addressed and resolved all the discrepancies to ensure full linguistic equivalence. The survey was approved by two major institutional review boards (Norwegian Centre for Research Data and Ohio University Office of Research Compliance). Informed consent was obtained from all respondents consistent with the Declaration of Helsinki.

The COVID-19 response stringency index (Oxford University 2020) shows that most countries worldwide had implemented their most restrictive policies by the 11th of May with the largest part of the global population facing some form of lockdown (Barbieri et al. 2020a; Sovacool et al. 2020). As several studies in cognitive psychology on human memory have indicated possible distortions and difficulty of recall from forgotten or telescoped events (Coughlin 1990; Solga 2001; Barsky 2002; Jaspers et al. 2009), responses to retrospective questions are considered reliable only for a relatively short period, generally ranging from some days to about a year (Smith 1984; Hipp et al. 2020). Therefore, by undertaking the survey in May 2020, it is assumed that all the survey participants were able to properly compare the air pollution "before" (retrospective question) and "during" (current question) the pandemic thanks to the short amount of time, ranging from some weeks to very few months, between the enforcement of the restrictions and the administration of the survey.

\section{Performed analyses}

The individual perceptions about the air pollution expressed according to the 7-point Likert scale were analysed and compared at a cross-country level. Furthermore, statistical analyses probed any possible correlations existing between the survey responses and the three demographic indicators considered (gender, age and education). The calculations were performed with the software package IBM SPSS Statistics version 27. The regression method employed was the Negative Binomial Model (NBM): NBM is a Generalised Linear Model and was selected as the hypotheses necessary to achieve simpler analyses (i.e. linear regression or ANOVA) were not fulfilled (i.e. normality of the residuals) (Ajide et al. 2020). Gender and education were regarded as categorical independent variables and age was treated as a continuous independent variable.

To test the extent to which the changes in air pollution related to $\mathrm{PM}_{2.5}, \mathrm{PM}_{10}$ and $\mathrm{O}_{3}$ are likely to trigger changes in air pollution perception, we also collected data for these air pollutants for two temporal frames, namely 01.01.2019-31.05.2019 and 01.01.2020-31.05.2020. As individual retrospective perceptions are most likely valid for a relatively short period as explained above, the pollutant concentrations were evaluated only for the 1-year time span. Consequently, the well-known interannual differences in atmospheric circulation, meteorology and emission sources were not analysed as part of this study.

The intensity of air pollution as a whole is expressed by an indicator called Actual Air Pollution Quantity (AAPQ). AAPQ is a weighted combination of the three considered air pollutants $\mathrm{PM}_{2.5}, \mathrm{PM}_{10}$ and $\mathrm{O}_{3}$ and is assessed by means of Principal Component Analysis (PCA), which is an orthogonal transformation employed to reduce the dimensionality of complex datasets to a lower dimension (Hotelling 1933).

The concentrations of $\mathrm{PM}_{2.5}, \mathrm{PM}_{10}, \mathrm{O}_{3}$ were retrieved from national Environmental Protection Agencies (EPAs) and national monitoring centres for each of the ten countries involved in this study, namely Australia (EPA South 
Australia 2020; EPA Victoria 2020; NSW Office of Environment and Heritage 2020), Brazil (CETESB Companhia Ambiental do Estado de São Paulo 2020; CETREL 2020), China (China National Environment Monitoring Centre 2020), Ghana (AirNow Department of State 2020), India (CPCB Central Pollution Control Board 2020), Iran (Department of Environment Iran 2020), Italy (ARPA Emilia-Romagna 2020; ARPA Lombardia 2020; ARPA Piemonte 2020), Norway (Luftkvalitet i Norge 2020), South Africa (SAAQIS South African Air Quality Information System 2020) and the USA (United States Environmental Protection Agency 2020). All measurements were derived from 1043 ground-based stations located in the regions/states/provinces/counties matching the geographical locations of the survey respondents.

\section{RESULTS AND DISCUSSION}

\section{Reach of the survey}

The geographical distribution and the demographic information of the survey respondents are depicted in Fig. 1. The online survey included a balanced representation of gender (male $50.9 \%$ and female $48.9 \%$ ) with a total of 9 394 participants. Respondents tended to be younger and middle-aged adults $(M=32.6, \mathrm{SD}=11.6)$ and were also largely comprised of those with higher levels of education (81.3\% held at least a bachelor's degree). Thus, the results here likely reflected changes in perceptions of middle class individuals with probable better awareness of issues pertinent to air pollution (Bickerstaff and Walker 2001), particularly in less wealthy countries where internet access to the online-administered survey is less ubiquitous. The survey sample, albeit substantial, was skewed from the overall population demographic composition and, therefore, should only be considered as tentatively indicative of the actual perception of the general public. The survey dataset formed is publicly available (Barbieri et al. 2020b).

Figure 1 also reports on the locations of all the groundbased monitoring stations adopted to retrieve data on the concentration of $\mathrm{PM}_{2.5}, \mathrm{PM}_{10}$ and $\mathrm{O}_{3}$. The positions of the monitoring stations for China and the USA are not shown on the map due to their large numbers (367 and 599, respectively), which would cover the entire areas shaded in the figure. Only one ground-based station was available in Ghana to monitor the amount of particulate matter in 2020 .

\section{Perceived pollution}

Considering the responses associated to the Likert scale varying from " $1=$ extremely low/absent" to "7 = extremely high", a general improvement in atmospheric quality was clearly perceived in all ten investigated countries $(M=4.08, \mathrm{SD}=1.61$ before restrictions, $M=2.84$, $\mathrm{SD}=1.28$ during restrictions), albeit to different extents as reported in Fig. 2. The perceptions are in line with other studies shedding light on the quantitative improvement in air quality, such as in Brazil (Dantas et al. 2020; Nakada and Urban 2020; Siciliano et al. 2020a b), China (Chen et al. 2020a b; Le et al. 2020; Li et al. 2020; Sicard et al. 2020; Wang and Su 2020), India (Lokhandwala and Gautam 2020; Mahato et al. 2020; Sharma et al. 2020; Singh et al. 2020; Srivastava et al. 2020; Yadav et al. 2020; Mishra et al. 2021), Iran (Ahmadi et al. 2020), Italy (Collivignarelli et al. 2020; Rugani and Caro 2020; Sicard et al. 2020) and the USA (Bashir et al. 2020; Berman and Ebisu 2020; Chen et al. 2020).

Compared to before the restrictions, the number of individuals describing the air pollution as "low", "very low" or "extremely low/absent" increased more than 3 times in Brazil, India, Italy and South Africa. Moreover, the amount of respondents reporting "extremely low/absent" changed from $3.5 \%$ to $23.9 \%$ (approximately 7 times) in India and from $0.2 \%$ to $10.3 \%$ (approximately 60 times) in Italy, respectively. Accordingly, the number of individuals depicting the level of atmospheric pollution as "high", "very high" or "extremely high" was significantly reduced, even in those countries where air pollution was perceived to be low before the pandemic (such as Australia and Norway). People's perceptions on air pollution reduction differ significantly between countries (Chi square test; $p<.001)$.

The mean responses were further considered; as reported in Fig. 3, the data points corresponding to those countries where respondents perceived a larger amount of pollution before the pandemic accounted for a larger drop in the Perceived Air Pollution Quantity (PAPQ) during the enactment of the restrictions. The fact that individuals from countries of greater atmospheric pollution perceived a much greater air quality improvement can be associated to the fact that human attitudes and decisions may not always be based on factuality, but on baseline conditions according to the theory of irrational perception and decision making (Tversky and Kahneman 1981; Kahneman and Tversky 1996; Bickerstaff 2004). Alternatively, this could also be due to the fact that individual experience can dictate current perceptions, known as the "hot-stove effect" (Graves 2003; Denrell and March 2001). The largest drop in PAPQ during the restriction was from respondents in India and Italy; on the other hand, Norwegian and Chinese survey participants perceived the smallest drop in PAPQ. In Fig. 3 the data point representing Chinese respondents is the farthest to the regression line $\left(R^{2}=0.4338\right)$. This represents an unexpected outcome considering the high pollution level of the country (Tong et al. 2014; Guo et al. 2016) 


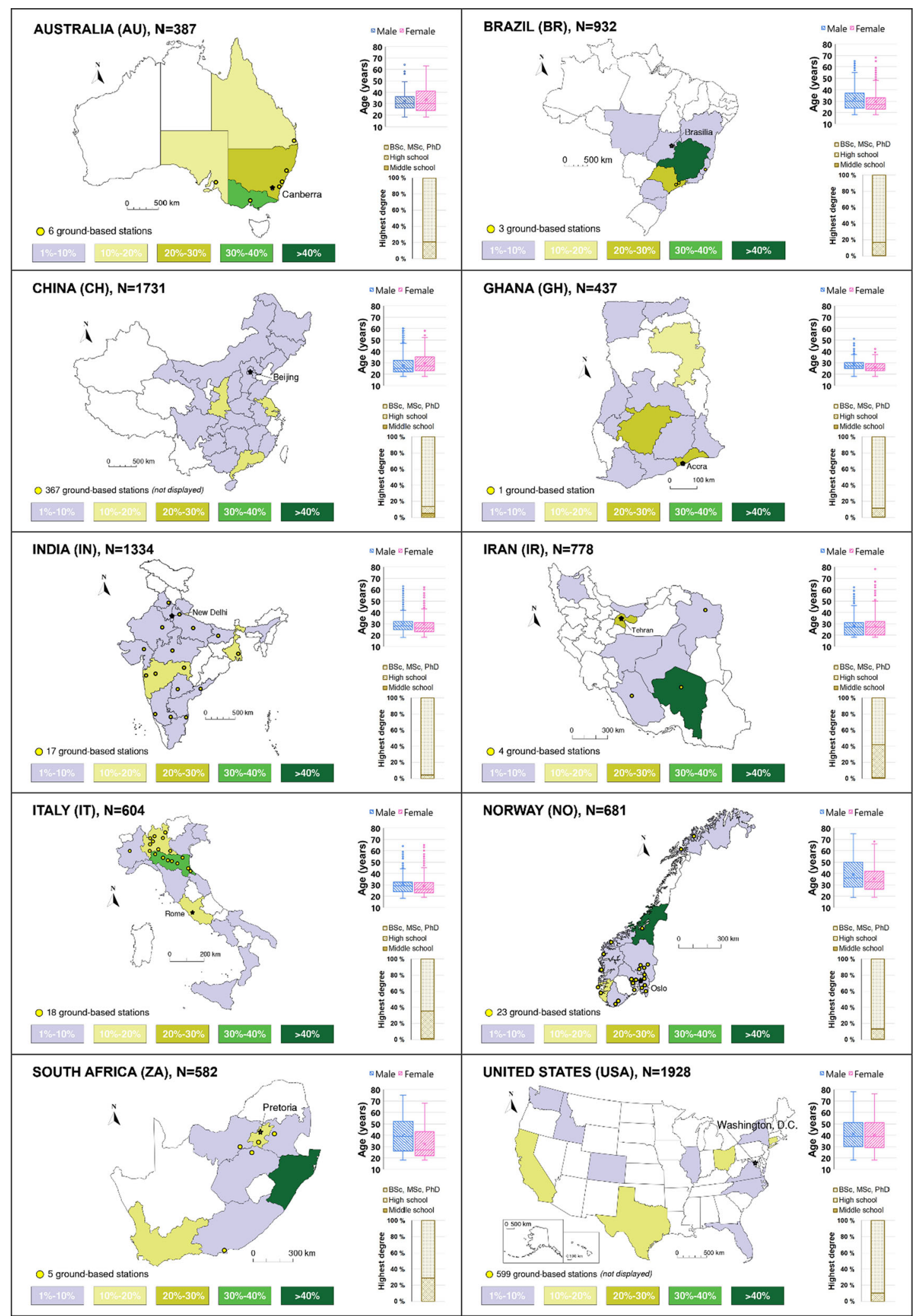

Fig. 1 Sample size, geographical distribution of respondents for each country (percent), age, gender and education split. Locations of groundbased monitoring stations (not displayed for China and the USA) 


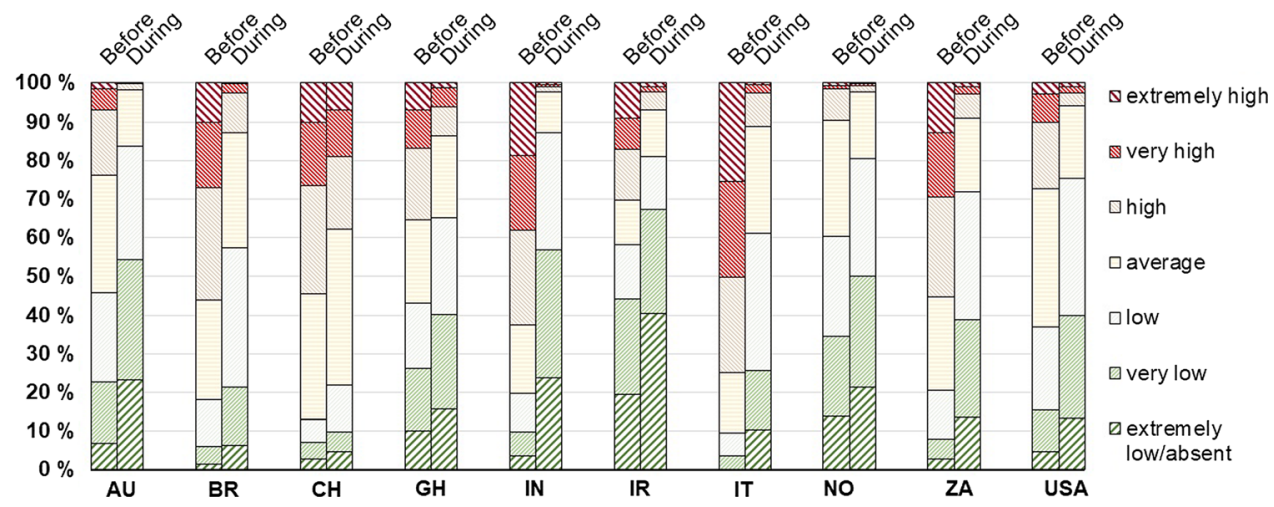

Fig. 2 Perceived Air Pollution Quantity (PAPQ) before and during the pandemic-related restrictive measures by the survey respondents

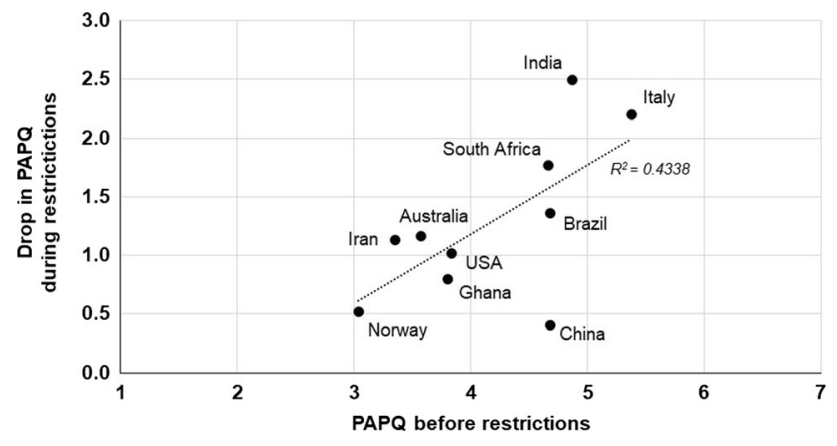

Fig. 3 Perceived Air Pollution Quantity (PAPQ) before the restrictions and drop in PAPQ during the restrictions by the survey respondents (Likert-type scoring system varying from " 1 = extremely low" to "7 = extremely high")

Table 1 Likelihood ratio Chi Square, deviance/df ratio, parameters estimates, standard deviation, and statistical significance $\left(B \pm\right.$ S.E. $\left.{ }^{\mathrm{x}}\right)$ for the responses on perceived pollution before and after the enactment of the pandemic-related restrictions

\begin{tabular}{lcc}
\hline & Before restrictions & During restrictions \\
\hline Likelihood ratio Chi Square & 12.704 & 15.669 \\
Deviance/df ratio & 0.150 & 0.162 \\
Parameters estimates & & \\
Male I Female & $-0.065 \pm 0.023^{* *}$ & $-0.051 \pm 0.024^{*}$ \\
Education 1 | 6 & $0.118 \pm 0.298^{\mathrm{ns}}$ & $0.284 \pm 0.304^{\mathrm{ns}}$ \\
Education 2 | 6 & $-0.019 \pm 0.118^{\mathrm{ns}}$ & $0.212 \pm 0.12^{\mathrm{ns}}$ \\
Education 3 | 6 & $-0.010 \pm 0.049^{\mathrm{ns}}$ & $0.002 \pm 0.051^{\mathrm{ns}}$ \\
Education 4 | 6 & $0.032 \pm 0.041^{\mathrm{ns}}$ & $0.068 \pm 0.043^{\mathrm{ns}}$ \\
Education 5 | 6 & $0.054 \pm 0.042^{\mathrm{ns}}$ & $0.029 \pm 0.044^{\mathrm{ns}}$ \\
Age & $-0.001 \pm 0.001^{\mathrm{ns}}$ & $-0.002 \pm 0.001^{\mathrm{ns}}$ \\
\hline
\end{tabular}

ns non-significant, "Education 1" Primary school, "Education 2" Middle school, "Education 3" High school, "Education 4" BSc,

"Education 5" MSc, "Education 6" $\mathrm{PhD}$

$* p<0.05, * * p<0.01$ and could reflect a legacy effect from the combination of long-term exposure to poor quality air and the lack of awareness (Huang and Yang 2020).

\section{Role of gender, age, education}

Considering the results of the statistical analyses displayed in Table 1, gender was the only significant predictor $(p<.05)$. As depicted in Figure S1, females generally perceived more air pollution. As for the other two variables education and age, no significant correlations were found. No collinearity issues between the three independent variables (gender, education and age) were detected while performing the analyses. Based on the existing literature, there appears to be a lack of univocal support regarding the significant demographic predictors of air pollution perception. The importance of gender as emerged in this study is in agreement with other investigations performed in different places of the globe also focussing on the same topic (Rotko et al. 2002; De Feo et al. 2013; Liao et al. 2015; Chakraborty et al. 2017; Cisneros et al. 2017). Contrastingly, previous studies demonstrated a significant correlation of pollution perception to education level (Klæboe et al. 2000; Badland and Duncan 2009) or age (Lercher et al. 1995; Liu et al. 2016) or all of the three social indicators (Lai and Tao 2003), while some investigations found no gender bias in perceptions of environmental concerns (Howel et al. 2003; Kim et al. 2012; Omanga et al. 2014; Becken et al. 2017).

\section{Indicative comparison of actual and perceived pollution}

The levels of air pollutants $\mathrm{PM}_{2.5}, \mathrm{PM}_{10}$ and $\mathrm{O}_{3}$ were extrapolated; the data retrieved were available on a 1-hour, 8-hour or 24-hour basis depending on each monitoring station. Average pollution levels in 2019 and 2020 are summarised in Table 2. From year to year, there were 
Table 2 Average values of particulate matter $\mathrm{PM}_{2.5}, \mathrm{PM}_{10}$ and ozone $\mathrm{O}_{3}$ evaluated between the 1st of January and the 31 st of May in 2019 and in 2020

\begin{tabular}{|c|c|c|c|c|c|c|c|c|c|c|c|}
\hline & & $\mathbf{A U}$ & BR & CH & GH & IN & IR & IT & NO & $\mathbf{Z A}$ & USA \\
\hline \multirow{3}{*}{$\begin{array}{c}\mathbf{P M}_{2.5} \\
\left(\mu \mathrm{g} / \mathbf{m}^{3}\right)\end{array}$} & 2019 & 24.42 & 47.05 & 44.40 & n.a. & 138.62 & 70.91 & 25.84 & 28.24 & 45.32 & 29.14 \\
\hline & 2020 & 26.18 & 33.33 & 38.60 & 37.53 & 43.83 & 65.41 & 17.13 & 6.27 & 28.06 & 5.89 \\
\hline & Change & $+7.2 \%$ & $-29.2 \%$ & $-13.1 \%$ & n.a. & $-68.4 \%$ & $-7.8 \%$ & $-33.7 \%$ & $-77.8 \%$ & $-38.1 \%$ & $-79.8 \%$ \\
\hline \multirow{3}{*}{$\begin{array}{c}\mathrm{PM}_{10} \\
\left(\mu \mathrm{g} / \mathrm{m}^{3}\right)\end{array}$} & 2019 & 14.93 & 19.33 & 81.31 & n.a. & 96.82 & 40.35 & 26.70 & 25.54 & 24.58 & 14.84 \\
\hline & 2020 & 16.41 & 13.33 & 66.37 & 52.25 & 94.10 & 35.49 & 17.78 & 13.34 & 28.47 & 14.27 \\
\hline & Change & $+9.9 \%$ & $-31.0 \%$ & $-18.4 \%$ & n.a. & $-2.8 \%$ & $-12.0 \%$ & $-33.4 \%$ & $-47.8 \%$ & $+15.8 \%$ & $-3.8 \%$ \\
\hline \multirow{3}{*}{$\begin{array}{c}\mathrm{O}_{3} \\
\left(\mu \mathrm{g} / \mathrm{m}^{3}\right)\end{array}$} & 2019 & 7.61 & 13.58 & 62.68 & n.a. & 15.59 & 31.16 & 43.14 & 25.28 & 7.18 & 29.62 \\
\hline & 2020 & 10.95 & 13.53 & 66.80 & n.a. & 37.87 & 31.58 & 49.88 & 69.67 & 8.54 & 88.65 \\
\hline & Change & $+43.9 \%$ & $-0.4 \%$ & $+6.6 \%$ & n.a. & $+142.9 \%$ & $+1.3 \%$ & $+15.6 \%$ & $+175.6 \%$ & $+18.9 \%$ & $+199.3 \%$ \\
\hline
\end{tabular}

n.a. not available

substantial reductions in particulate matter in eight countries. Conversely, Australia saw increments in both $\mathrm{PM}_{2.5}$ and $\mathrm{PM}_{10}$, most likely due to extremely high concentrations in January 2020 concurrent with the severe bushfire season (Jalaludin et al. 2020). In general, $\mathrm{PM}_{2.5}$ had a deeper decline than $\mathrm{PM}_{10}$ : the average decreases, assessed from all the ten countries, were $-21.03 \mu \mathrm{g} / \mathrm{m}^{3}$ and $-4.98 \mu \mathrm{g} /$ $\mathrm{m}^{3}$, respectively. The most significant drops were registered in India for $\mathrm{PM}_{2.5}\left(-94.79 \mu \mathrm{g} / \mathrm{m}^{3}\right)$ and in China for $\mathrm{PM}_{10}\left(-14.93 \mu \mathrm{g} / \mathrm{m}^{3}\right)$. For ozone, concentrations generally increased in 2020 with respect to 2019. Considering mean values, the largest hikes were registered in the USA $\left(+59.03 \mu \mathrm{g} / \mathrm{m}^{3}\right)$ and Norway $\left(+44.38 \mu \mathrm{g} / \mathrm{m}^{3}\right)$. Increases in ozone concentrations are not necessarily inconsistent with overall better air quality and the reduction of other pollutants (Sillman and He 2002; Li et al. 2019a b c; Mahato et al. 2020; Siciliano et al. 2020b).

Considering the drop in PAPQ versus the registered drop in AAPQ (Fig. 4), a positive and weak correlation is found $\left(\mathrm{R}^{2}=0.1315\right)$. In addition, the relationships between the

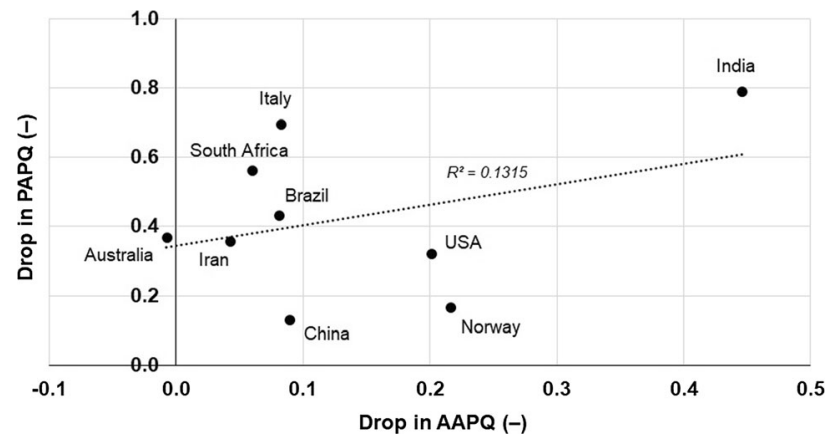

Fig. 4 Comparison between drop in Perceived Air Pollution Quantity (PAPQ) and drop in Actual Air Pollution Quantity (AAPQ) variation in concentration of each pollutant and PAPQ are reported in Figure S2 as separate entities to match the initial source categories.

It must be noted that there are certain limitations related to the calculations of $\mathrm{PM}_{2.5}, \mathrm{PM}_{10}$ and $\mathrm{O}_{3}$ performed in this study. Pollutant concentrations may fluctuate according to the change in atmospheric circulation due to seasonal disparity between southern and northern hemispheres, while locations with different irradiation and rainfall patterns may be related to specific wet scavenging processes of air pollutants (Elperin et al. 2011; Berman and Ebisu 2020). Moreover, as it was not possible to assess the precise distance between survey respondents and ground-based monitoring stations, no inverse distance weighting could be applied to adjust the exposure. Therefore, the findings connecting the variation in the pollutants concentration and the individual perceptions should be considered indicative only. There was not enough data available for Ghana to be included in the discussion of results.

\section{CONCLUSIONS}

Activities from human settlements are responsible for significant amounts of pollution externalities, which in turn lead to physical and psychologic detrimental effects on human well-being. This study focussed on the perception of the air pollution in ten countries (Australia, Brazil, China, Ghana, India, Iran, Italy, Norway, South Africa and the USA) in conjunction with the reduction in the hazardous emissions released into the troposphere during the enforcement of the COVID-19 pandemic restrictions. An online survey administered in May 2020 collected 
information about the level of air pollution perceived by individuals $(N=9$ 394) before and during the COVID-19 mitigation measures. The following conclusions can be drawn:

(1) Albeit at different extents, all survey respondents expressed a significant improvement in the air quality and such positive public perception should be considered a motivation for long-term systemic change for mitigating air pollution worldwide. The most striking decreases in poor air quality were perceived in India and Italy. Conversely, the smallest variations were perceived among Chinese and Norwegian respondents (see reason below).

(2) People from different countries did experience an improvement in air quality in conjunction with the implementation of the pandemic-related mitigation measures. However, considering the central role of publicity around air pollution as a crucial factor for stimulating public awareness, individuals are likely to underestimate the improvement in air quality nor to identify the level of air pollution in an unbiased fashion.

(3) Among the demographic indicators considered, the air quality perceptions of the surveyed population strongly hinged upon one factor: gender. Compared to male respondents, female respondents perceived a higher amount of air pollution, both before and during the pandemic-related restrictions. Neither education nor age were found to be significant sociodemographic indicators for air pollution perception.

(4) Based on the indicative comparison performed between the levels of actual and perceived atmospheric pollution, a positive and weak relationship was found. Therefore, being the pollution experienced as a personal combination of olfactory and visual impacts, individuals are not amenable to perceive air quality objectively.

The remarkable reduction in air pollution during the COVID-19 pandemic may just be temporary and may revert to previous trends if both the citizenry and policymakers do not realise the "pervasive, omnipresent and interdependent" lessons learned (Bergman 2020; McNeely 2021). The cross-sectional nature of this study prevented the opportunity to disentangle whether the respondents' perceptions were biased by local and global media coverage or specific neighbourhood characteristics (Sax et al. 2003; Earl et al. 2004; Oltra and Sala 2014). The findings indicate that policies and strategies for air quality enhancement must be planned strategically with the realisation that public acceptance may not be straightforward and can be gender dependent. Further environmental parameters, which may affect the overall comfort of the individuals, can be taken into consideration in future research to delve into the behavioural impacts and the psychological consequences of air pollution.

Acknowledgements This research has not received any specific grant from funding agencies in the public, commercial or not-forprofit sectors. The precious support kindly provided by the following academics, researchers and professionals has been greatly appreciated: Mr. Fabio Selva (Heilongjiang International University, China), Mr. Marius Tangerås (Norwegian National Railway Administration Bane NOR, Norway), Dr. Azadeh Lak (Shahid Beheshti University, Iran), Dr. Barbara Stolte Bezerra (Universidade Estadual Paulista, Brazil), Dr. Xiaolong Sun (Guangdong University of Technology, China), Dr. Abdul Rahaman (Bharathidasan University, India), Dr. Dok Yen David Mbabil (Tamale Technical University, Ghana), Mr. Smit Bharat Thakkar (Queensland University of Technology, Australia), Mr. Solomon Kwadwo Achinah (University of Cape Coast, Ghana), Dr. Olaf Weyl (South African Institute for Aquatic Biodiversity, South Africa), Mr. Ayush Dhankute (Atkins Ltd., India), Mr. Mohammadreza Zare Reisabadi (University of Adelaide, Australia), Dr. Sachin Gunthe (Indian Institute of Technology Madras, India), Dr. Issam Qamhia (University of Illinois at Urbana-Champaign, USA), Dr. Parama Bannerji (West Bengal College, India), Mr. Amirhosein Mousavi (University of Southern California, United States), Mr. Anshu Bamney (Rewa Engineering College, India), Dr. Yuefeng Zhu (Shijiazhuang Tiedao University, China), Dr. Jorge Ubirajara Pedreira Junior (Federal University of Bahia, Brazil), Dr. Andrea Colagrossi (Politecnico di Milano, Italy) and Dr. Akhilesh Kumar Maurya (Indian Institute of Technology Guwahati, India).

Funding Open access funding provided by NTNU Norwegian University of Science and Technology (incl St. Olavs Hospital Trondheim University Hospital).

Open Access This article is licensed under a Creative Commons Attribution 4.0 International License, which permits use, sharing, adaptation, distribution and reproduction in any medium or format, as long as you give appropriate credit to the original author(s) and the source, provide a link to the Creative Commons licence, and indicate if changes were made. The images or other third party material in this article are included in the article's Creative Commons licence, unless indicated otherwise in a credit line to the material. If material is not included in the article's Creative Commons licence and your intended use is not permitted by statutory regulation or exceeds the permitted use, you will need to obtain permission directly from the copyright holder. To view a copy of this licence, visit http://creativecommons. org/licenses/by/4.0/.

\section{REFERENCES}

Acter, T., N. Uddin, J. Das, A. Akhter, T.R. Choudhury, and S. Kim. 2020. Evolution of severe acute respiratory syndrome coronavirus 2 (SARS-CoV-2) as coronavirus disease 2019 (COVID19) pandemic: A global health emergency. Science of the Total Environment. https://doi.org/10.1016/j.scitotenv.2020.138996.

Ahmadi, M., A. Sharifi, S. Dorosti, S. Jafarzadeh Ghoushchi, and N. Ghanbari. 2020. Investigation of effective climatology parameters on COVID-19 outbreak in Iran. Science of the Total Environment. https://doi.org/10.1016/j.scitotenv.2020.138705. 
AirNow Department of State. 2020. AirNow Department of State [WWW Document]. https://www.airnow.gov/international/usembassies-and-consulates/\#Ghana\$Accra. Accessed Jan 82020.

Ajide, K.B., R.L. Ibrahim, and O.Y. Alimi. 2020. Estimating the impacts of lockdown on Covid-19 cases in Nigeria. Transportation Research Interdisciplinary Perspectives. https://doi.org/10. 1016/j.trip.2020.100217.

Alshaabi, T., M.V. Arnold, J.R. Minot, J.L. Adams, D.R. Dewhurst, A.J. Reagan, R. Muhamad, C.M. Danforth, et al. 2021. How the world's collective attention is being paid to a pandemic: COVID-19 related n-gram time series for 24 languages on Twitter. PLoS ONE 16: 1-13. https://doi.org/10.1371/journal. pone.0244476.

Andreoni, V. 2021. Estimating the European $\mathrm{CO}_{2}$ emissions change due to COVID-19 restrictions. Science of the Total Environment 769: 145115 .

ARPA Emilia-Romagna. 2020. ARPA Emilia-Romagna [WWW Document]. https://www.arpae.it/index.asp?idlivello=134. Accessed Jan 82020.

ARPA Lombardia. 2020. ARPA Lombardia [WWW Document]. URL https://www.arpalombardia.it/Pages/ARPA_Home_Page. aspx. Accessed 8 Jan 2020.

ARPA Piemonte. 2020. ARIAWEB [WWW Document]. URL http:// www.regione.piemonte.it/ambiente/aria/rilev/ariaday/ariawebnew/index.php/en/home. Accessed 8 Jan 2020.

Badland, H.M., and M.J. Duncan. 2009. Perceptions of air pollution during the work-related commute by adults in Queensland, Australia. Atmospheric Environment 43: 5791-5795. https://doi. org/10.1016/j.atmosenv.2009.07.050.

Barbieri, D.M., B. Lou, M. Passavanti, C. Hui, D. Antunes, B. Maharaj, A. Banerjee, F. Wang, et al. 2020a. A survey dataset to evaluate the changes in mobility and transportation due to COVID-19 travel restrictions in Australia, Brazil, China, Ghana, India, Iran, Italy, Norway, South Africa, United States. Data Br. https://doi.org/10.1016/j.dib.2020.106459.

Barbieri, D.M., B. Lou, M. Passavanti, C. Hui, I. Hoff, D.A. Lessa, G. Sikka, K. Chang, et al. 2021. Impact of COVID-19 pandemic on mobility in ten countries and associated perceived risk for all transport modes. PLOS ONE. https://doi.org/10.1371/journal. pone. 0245886 .

Barbieri, D.M., B. Lou, M. Passavanti, C. Hui, D.A. Lessa, B. Maharaj, A. Banerjee, F. Wang, et al. 2020b. Survey data regarding perceived air quality in Australia, Brazil, China, Ghana, India, Iran, Italy, Norway, South Africa, United States before and during COVID-19 restrictions. Data BR. https://doi. org/10.1016/j.dib.2020.106169.

Barsky, A.J. 2002. Forgetting, fabricating, and telescoping. Archives of Internal Medicine 162: 981. https://doi.org/10.1001/archinte. 162.9 .981

Barua, S., and S.D. Nath. 2021. The impact of COVID-19 on air pollution: Evidence from global data. Journal of Cleaner Production. https://doi.org/10.2139/ssrn.3644198.

Bashir, M.F., B. Komal, M.A. Bashir, T.H. Farooq, N. Iqbal, and M. Bashir. 2020. Correlation between environmental pollution indicators and COVID-19 pandemic: A brief study in Californian context. Environmental Research. https://doi.org/10.1016/j. envres.2020.109652.

Beaumont, R., R.S. Hamilton, N. Machin, J. Perks, and I.D. Williams. 1999. Social awareness of air quality information. Science of the Total Environment 235: 319-329. https://doi.org/10.1016/ S0048-9697(99)00215-6.

Becken, S., X. Jin, C. Zhang, and J. Gao. 2017. Urban air pollution in China: destination image and risk perceptions. Journal of Sustainable Tourism 25: 130-147. https://doi.org/10.1080/ 09669582.2016 .1177067$.
Bergman, M.M. 2020. The world after COVID. World 1: 45-48. https://doi.org/10.3390/world1010005.

Berman, J.D., and K. Ebisu. 2020. Changes in US air pollution during the COVID-19 pandemic. Science of the Total Environment. https://doi.org/10.1016/j.scitotenv.2020.139864.

Bickerstaff, K. 2004. Risk perception research: Socio-cultural perspectives on the public experience of air pollution. Environment International 30: 827-840. https://doi.org/10.1016/j.envint. 2003.12.001.

Bickerstaff, K., and G. Walker. 2001. Public understandings of air pollution: The "localisation" of environmental risk. Global Environmental Change 11: 133-145. https://doi.org/10.1016/ S0959-3780(00)00063-7.

Bickerstaff, K., and G. Walker. 1999. Clearing the smog? Public responses to air-quality information. Local Environment 4: 279-294. https://doi.org/10.1080/13549839908725600.

Brimblecombe, P., and Y. Lai. 2020. Effect of fireworks, Chinese new year and the COVID-19 lockdown on air pollution and public attitudes. Aerosol and Air Quality Research 20: 2318-2331. https://doi.org/10.4209/aaqr.2020.06.0299.

Brimblecombe, P., and H. Zong. 2019. Citizen perception of APEC blue and air pollution management. Atmos Environment. https:// doi.org/10.1016/j.atmosenv.2019.116853.

Brislin, R.W. 1976. Comparative research methodology: Crosscultural studies. International Journal of Psychology. 10.1080/ 00207597608247359.

Burnett, R., H. Chen, M. Szyszkowicz, N. Fann, B. Hubbell, C.A. Pope, J.S. Apte, M. Brauer, et al. 2018. Global estimates of mortality associated with longterm exposure to outdoor fine particulate matter. Proceedings of the National academy of Sciences of the United States of America 115: 9592-9597. https://doi.org/10.1073/pnas.1803222115.

Bush, J., S. Moffatt, and C. Dunn. 2001a. "Even the birds round here cough": Stigma, air pollution and health in Teesside. Heal. Place 7: 47-56. https://doi.org/10.1016/S1353-8292(00)00037-X.

Bush, J., S. Moffatt, and C.E. Dunn. 2001b. Keeping the public informed? Public negotiation of air quality information. Public Understanding of Science 10: 213-228. https://doi.org/10.1088/ 0963-6625/10/2/304.

Casado-Aranda, L.A., J. Sánchez-Fernández, M.I. Viedma-del-Jesús. 2020. Analysis of the scientific production of the effect of COVID-19 on the environment: A bibliometric study. Environment Research. https://doi.org/10.1016/j.envres.2020.110416.

CETESB - Companhia Ambiental do Estado de São Paulo. 2020. CETESB - Companhia Ambiental do Estado de São Paulo [WWW Document]. https://cetesb.sp.gov.br/. Accessed 8 Jan 2020.

CETREL. 2020. CETREL [WWW Document]. http://www.cetrel. com.br/.

Chakraborty, J., T.W. Collins, S.E. Grineski, and A. Maldonado. 2017. Racial differences in perceptions of air pollution health risk: Does environmental exposure matter? International Journal of Environmental Research and Public Health 14: 17-20. https:// doi.org/10.3390/ijerph14020116.

Chauhan, A., R.P. Singh, 2020. Decline in PM2.5 concentrations over major cities around the world associated with COVID-19. Environmental Research. https://doi.org/10.1016/j.envres.2020. 109634.

Chen, L.-C., Y. Li, and G. Lin. 2020a. Nonuniform impacts of COVID-19 lockdown on air quality over the United States. Science of the Total Environment. https://doi.org/10.1016/j. scitotenv.2020.141105.

Chen, Y., S. Zhang, C. Peng, G. Shi, M. Tian, R.-J. Huang, D. Guo, H. Wang, et al. 2020b. Impact of the COVID-19 pandemic and control measures on air quality and aerosol light absorption in 
Southwestern China. Science of the Total Environment. https:// doi.org/10.1016/j.scitotenv.2020.141419.

China National Environment Monitoring Centre. 2020. China National Environment Monitoring Centre [WWW Document]. https://quotsoft.net/air/. Accessed 8 Jan 2020.

Cisneros, R., P. Brown, L. Cameron, E. Gaab, M. Gonzalez, S. Ramondt, D. Veloz, A. Song, et al. 2017. Understanding public views about air quality and air pollution sources in the san Joaquin Valley, California. Journal of Environmental and Public Health. https://doi.org/10.1155/2017/4535142.

Cohen, A.J., M. Brauer, R. Burnett, H.R. Anderson, J. Frostad, K. Estep, K. Balakrishnan, B. Brunekreef, et al. 2017. Estimates and 25 -year trends of the global burden of disease attributable to ambient air pollution: An analysis of data from the Global Burden of Diseases Study 2015. Lancet 389: 1907-1918. https:// doi.org/10.1016/S0140-6736(17)30505-6.

Collivignarelli, M.C., A. Abbà, G. Bertanza, R. Pedrazzani, P. Ricciardi, and M. Carnevale Miino. 2020. Lockdown for CoViD2019 in Milan: What are the effects on air quality? Science of the Total Environment. https://doi.org/10.1016/j.scitotenv.2020. 139280.

Coughlin, S.S. 1990. Recall bias in epidemiologic studies. Journal of Clinical Epidemiology 43: 87-91. https://doi.org/10.1016/08954356(90)90060-3.

CPCB Central Pollution Control Board, 2020. CPCB Central Pollution Control Board [WWW Document]. http://www.cpcb. nic.in/. Accessed 8 Jan 2020

Crowe, M.J. 1968. Toward a "definitional model" of public perceptions of air pollution. Journal of the Air and Waste Management Association 18: 154-157. https://doi.org/10.1080/ 00022470.1968 .10469106$.

Dantas, G., B. Siciliano, B.B. França, C.M. da Silva, and G. Arbilla. 2020. The impact of COVID-19 partial lockdown on the air quality of the city of Rio de Janeiro, Brazil. Science of the Total Environment. https://doi.org/10.1016/j.scitotenv.2020.139085.

De Beuckelaer, A., and F. Lievens. 2009. Measurement equivalence of paper-and-pencil and internet organisational surveys: A large scale examination in 16 countries. Applied Psychology 58: 336-361. https://doi.org/10.1111/j.1464-0597.2008.00350.x.

De Feo, G., S. De Gisi, and I.D. Williams. 2013. Public perception of odour and environmental pollution attributed to MSW treatment and disposal facilities: A case study. Waste Manag. 33: 974-987. https://doi.org/10.1016/j.wasman.2012.12.016.

de Groot, I. 1967. Trends in public attitudes toward air pollution. Journal of the Air and Waste Management Association 17: 679-681. https://doi.org/10.1080/00022470.1967.10469056.

De Vos, J. 2020. The effect of COVID-19 and subsequent social distancing on travel behavior. Transportation Research Interdisciplinary Perspectives. https://doi.org/10.1016/j.trip.2020. 100121.

Deguen, S., C. Ségala, G. Pédrono, and M. Mesbah. 2012. A new air quality perception scale for global assessment of air pollution health effects. Risk Analysis 32: 2043-2054. https://doi.org/10. 1111/j.1539-6924.2012.01862.x.

Denrell, J., and J.G. March. 2001. Adaptation as information restriction: The hot stove effect. Organization Science 12: 523-538. https://doi.org/10.1287/orsc.12.5.523.10092.

Department of Environment Iran, 2020. Department of Environment Iran [WWW Document]. https://fars.doe.ir/portal/home/. Accessed 8 Jan 2020.

Earl, J., A. Martin, J.D. McCarthy, and S.A. Soule. 2004. The use of newspaper data in the study of collective action. Annual Review of Sociology 30: 65-80. https://doi.org/10.1146/annurev.soc.30. 012703.110603 .

Elperin, T., A. Fominykh, B. Krasovitov, and A. Vikhansky. 2011. Effect of rain scavenging on altitudinal distribution of soluble gaseous pollutants in the atmosphere. Atmospheric Environment 45: 2427-2433. https://doi.org/10.1016/j.atmosenv.2011.02.008.

EPA South Australia. 2020. EPA South Australia [WWW Document]. http://www.epa.sa.gov.au/. Accessed 8 Jan 2020.

EPA Victoria. 2020. EPA Victoria [WWW Document]. https://www. epa.vic.gov.au/. Accessed 8 Jan 2020.

ESA. 2020. Copernicus [WWW Document]. https://www.esa.int/ Applications/Observing_the_Earth/Copernicus. Accessed 8 Jan 2020.

Feng, Z., A. De Marco, A. Anav, M. Gualtieri, P. Sicard, H. Tian, F. Fornasier, F. Tao, et al. 2019. Economic losses due to ozone impacts on human health, forest productivity and crop yield across China. Environment International. https://doi.org/10. 1016/j.envint.2019.104966.

Friedman, M.S., K.E. Powell, L. Hutwagner, L.R.M. Graham, and W.G. Teague. 2001. Impact of changes in transportation and commuting behaviors during the 1996 Summer Olympic Games in Atlanta on air quality and childhood asthma. Journal of the American Medical Association 285: 897-905. https://doi.org/10. 1001/jama.285.7.897.

Graves, P.E. 2003. Environmental perceptions and environmental reality when more is less. Journal of Environmental Planning and Management 35: 951-954. https://doi.org/10.1068/ a3506 com.

Guo, Y., H. Zeng, R. Zheng, S. Li, A.G. Barnett, S. Zhang, X. Zou, R. Huxley, et al. 2016. The association between lung cancer incidence and ambient air pollution in China: A spatiotemporal analysis. Environmental Research 144: 60-65. https://doi.org/10. 1016/j.envres.2015.11.004.

Hamra, G.B., N. Guha, A. Cohen, F. Laden, O. Raaschou-Nielsen, J.M. Samet, P. Vineis, F. Forastiere, et al. 2014. Outdoor particulate matter exposure and lung cancer: A systematic review and meta-analysis. Environmental Health Perspectives 122: 906-911. https://doi.org/10.1289/ehp.1408092.

Hipp, L., M. Bünning, S. Munnes, and A. Sauermann. 2020. Problems and pitfalls of retrospective survey questions in COVID-19 studies. Survey Research Methods 14, 109-114. https://doi.org/ 10.18148/srm/2020.v14i2.7741.

Hoek, G., R.M. Krishnan, R. Beelen, A. Peters, B. Ostro, B. Brunekreef, and J.D. Kaufman. 2013. Long-term air pollution exposure and cardio-respiratory mortality: A review. Environmental Health 12: 1-15. https://doi.org/10.1186/1476-069X-1243.

Hotelling, H. 1933. Analysis of a complex of statistical variables into Principal Components. J. Educ. Psychol. 24, 417-441. https:// doi.org/10.1037/h0071325.

Howel, D., S. Moffatt, J. Bush, C.E. Dunn, and H. Prince. 2003. Public views on the links between air pollution and health in Northeast England. Environmental Research 91: 163-171. https://doi.org/10.1016/S0013-9351(02)00037-3.

Huang, J., and J.Z. Yang. 2020. Beyond under the dome: an environmental documentary amplified public risk perception about air pollution in China. Journal of Risk Research 23: 227-241. https://doi.org/10.1080/13669877.2019.1569090.

Huang, W., G. Wang, S.E. Lu, H. Kipen, Y. Wang, M. Hu, W. Lin, D. Rich, et al. 2012. Inflammatory and oxidative stress responses of healthy young adults to changes in air quality during the Beijing Olympics. American Journal of Respiratory and Critical Care Medicine 186: 1150-1159. https://doi.org/10.1164/rccm.2012050850OC.

Ito, K., S. Inoue, Y. Hiraku, and S. Kawanishi. 2005. Mechanism of site-specific DNA damage induced by ozone. Mutation Research 585: 60-70. https://doi.org/10.1016/j.mrgentox.2005.04.004.

Jalaludin, B., F. Johnston, S. Vardoulakis, and G. Morgan. 2020. Reflections on the catastrophic 2019-2020 Australian bushfires. Innovation 1: https://doi.org/10.1016/j.xinn.2020.04.010. 
Jaspers, E., M. Lubbers, and N.D. De Graaf. 2009. Measuring once twice: An evaluation of recalling attitudes in survey research. European Sociological Review 25: 287-301. https://doi.org/10. 1093/esr/jcn048.

Kahneman, D., Tversky, A. 1996. On the reality of cognitive illusions. Psychol. Rev. 103, 582-591. https://doi.org/10.1037/ 0033-295X.103.3.582.

Kim, M., O. Yi, and H. Kim. 2012. The role of differences in individual and community attributes in perceived air quality. Science of the Total Environment 425: 20-26. https://doi.org/10. 1016/j.scitotenv.2012.03.016.

Klæboe, R., M. Kolbenstvedt, J. Clench-Aas, and A. Bartonova. 2000. Oslo traffic study - part 1: An integrated approach to assess the combined effects of noise and air pollution on annoyance. Atmospheric Environment 34: 4727-4736. https://doi.org/10. 1016/s1352-2310(00)00304-6.

Kumari, P., and D. Toshniwal. 2020. Impact of lockdown on air quality over major cities across the globe during COVID-19 pandemic. Urban Climate. https://doi.org/10.1016/j.uclim.2020. 100719.

Lai, J.C.L., and J. Tao. 2003. Perception of environmental hazards in Hong Kong Chinese. Risk Analysis 23: 669-684. https://doi.org/ 10.1111/1539-6924.00346.

Lal, P., A. Kumar, S. Kumar, S. Kumari, P. Saikia, A. Dayanandan, D. Adhikari, and M.L. Khan. 2020. The dark cloud with a silver lining: Assessing the impact of the SARS COVID-19 pandemic on the global environment. Science of the Total Environment 732: https://doi.org/10.1016/j.scitotenv.2020.139297.

Le Quéré, C., R.B. Jackson, M.W. Jones, A.J.P. Smith, S. Abernethy, R.M. Andrew, A.J. De-Gol, D.R. Willis, et al. 2020. Temporary reduction in daily global CO2 emissions during the COVID-19 forced confinement. Nature Climate Change 10: 647-653. https://doi.org/10.1038/s41558-020-0797-x.

Le, T., Y. Wang, L. Liu, J. Yang, Y.L. Yung, G. Li, J.H. Seinfeld. 2020. Unexpected air pollution with marked emission reductions during the COVID-19 outbreak in China. Science (80-.). https:// doi.org/10.1126/science.abb7431.

Lelieveld, J., J.S. Evans, M. Fnais, D. Giannadaki, and A. Pozzer. 2015. The contribution of outdoor air pollution sources to premature mortality on a global scale. Nature 525: 367-371. https://doi.org/10.1038/nature15371.

Lercher, P., R. Schmitzberger, and W. Kofler. 1995. Perceived traffic air pollution, associated behavior and health in an alpine area. Science of the Total Environment 169: 71-74. https://doi.org/10. 1016/0048-9697(95)04634-D.

Li, X., M. Jin, X. Zhang, and S. Wang. 2019a. Globally analysing spatiotemporal trends of anthropogenic PM2.5 concentration and population's PM2.5 exposure from 1998 to 2016. Environment International 128: 46-62. https://doi.org/10.1016/j.envint.2019. 04.026 .

Li, K., D.J. Jacob, H. Liao, L. Shen, Q. Zhang, and K.H. Bates. 2019b. Anthropogenic drivers of 2013-2017 trends in summer surface ozone in China. Proceedings of the National Academy of Sciences of the USA 116: 422-427. https://doi.org/10.1073/pnas. 1812168116.

Li, L., Q. Li, L. Huang, Q. Wang, A. Zhu, J. Xu, Z. Liu, H. Li, et al. 2020. Air quality changes during the COVID-19 lockdown over the Yangtze River Delta Region: An insight into the impact of human activity pattern changes on air pollution variation. Science of the Total Environment. https://doi.org/10.1016/j. scitotenv.2020.139282.

Li, F., H. Yin, and X. Li. 2019c. Mega events and urban air quality improvement: A temporary show? Journal of Cleaner Production 217: 116-126. https://doi.org/10.1016/j.jclepro.2019.01.116.

Li, Y., D. Guan, S. Tao, X. Wang, and K. He. 2018. A review of air pollution impact on subjective well-being: Survey versus visual psychophysics. Journal of Cleaner Production 184: 959-968. https://doi.org/10.1016/j.jclepro.2018.02.296.

Liao, X., H. Tu, J.E. Maddock, S. Fan, G. Lan, Y. Wu, Z.K. Yuan, and Y. Lu. 2015. Residents' perception of air quality, pollution sources, and air pollution control in Nanchang, China. Atmospheric Pollution Research 6: 835-841. https://doi.org/10.5094/ APR.2015.092.

Liu, Q., A.S. Malarvizhi, W. Liu, H. Xu, J.T. Harris, J. Yang, D.Q. Duffy, M.M. Little, et al. 2021. Spatiotemporal changes in global nitrogen dioxide emission due to COVID-19 mitigation policies. Science of the Total Environment 776: https://doi.org/10.1016/j. scitotenv.2021.146027.

Liu, X., H. Zhu, Y. Hu, S. Feng, Y. Chu, Y. Wu, C. Wang, Y. Zhang, et al. 2016. Public's health risk awareness on urban air pollution in Chinese megacities: The cases of Shanghai, Wuhan and Nanchang. International Journal of Environmental Research and Public Health. https://doi.org/10.3390/ijerph13090845.

Lokhandwala, S., P. Gautam. 2020. Indirect impact of COVID-19 on Environment: A brief study in Indian Context. Environ. Res. https://doi.org/10.1016/j.envres.2020.109807.

Luftkvalitet i Norge. 2020. Luftkvalitet i Norge [WWW Document]. https://luftkvalitet.miljostatus.no/. Accessed 8 Jan 2020.

Mahato, S., S. Pal, and K.G. Ghosh. 2020. Effect of lockdown amid COVID-19 pandemic on air quality of the megacity Delhi, India. Science of the Total Environment. https://doi.org/10.1016/j. scitotenv.2020.139086.

Maione, M., E. Mocca, K. Eisfeld, Y. Kazepov, and S. Fuzzi. 2021. Public perception of air pollution sources across Europe. Ambio. 50: 1150-1158. https://doi.org/10.1007/s13280-020-01450-5.

McNeely, J.A. 2021. Nature and COVID-19: The pandemic, the environment, and the way ahead. Ambio. 50: 767-781. https:// doi.org/10.1007/s13280-020-01447-0.

Mishra, G., K. Ghosh, A. Kumar, M. Kumar, S. Kumar, S. Chintalapati, and S.N. Tripathi. 2021. An application of probability density function for the analysis of PM25 concentration during the COVID-19 lockdown period. Science of the Total Environment. https://doi.org/10.1016/j.scitotenv.2021. 146681.

Muhammad, S., X. Long, and M. Salman. 2020. COVID-19 pandemic and environmental pollution: A blessing in disguise? Science of the Total Environment 728: https://doi.org/10.1016/j.scitotenv. 2020.138820.

Nakada, L.Y.K., and R.C. Urban. 2020. COVID-19 pandemic: Impacts on the air quality during the partial lockdown in São Paulo state, Brazil. Science of the Total Environment 730: https://doi.org/10.1016/j.scitotenv.2020.139087.

NASA. 2020a. How the Coronavirus is (and is not) affecting the environment [WWW Document]. https://earthobservatory.nasa. gov/blogs/earthmatters/2020/03/05/how-the-coronavirus-is-andis-not-affecting-the-environment/. Accessed 8 Jan 2020.

NASA. 2020b. NASA satellite data show 30 percent drop in air pollution over northeast U.S. [WWW Document]. https://www. nasa.gov/feature/goddard/2020/drop-in-air-pollution-overnortheast. Accessed 8 Jan 2020.

NASA. 2020c. Airborne particle levels plummet in northern India [WWW Document]. https://earthobservatory.nasa.gov/images/ 146596/airborne-particle-levels-plummet-in-northern-india. Accessed 8 Jan 2020.

Nikolopoulou, M., J. Kleissl, P.F. Linden, and S. Lykoudis. 2011. Pedestrians' perception of environmental stimuli through field surveys: Focus on particulate pollution. Science of the Total Environment 409: 2493-2502. https://doi.org/10.1016/j. scitotenv.2011.02.002.

NSW Office of Environment and Heritage. 2020. NSW Office of Environment and Heritage [WWW Document]. https://www. environment.nsw.gov.au/. Accessed 8 Jan 2020. 
Nuvolone, D., D. Petri, and F. Voller. 2018. The effects of ozone on human health. Environmental Science and Pollution Research 25: 8074-8088. https://doi.org/10.1007/s11356-017-9239-3.

Oltra, C., R. Sala. 2014. A review of the social research on public perception and engagement practices in urban air pollution.

Omanga, E., L. Ulmer, Z. Berhane, and M. Gatari. 2014. Industrial air pollution in rural Kenya: Community awareness, risk perception and associations between risk variables. BMC Public Health. https://doi.org/10.1186/1471-2458-14-377.

Oxford University. 2020. Coronavirus government response tracker [WWW Document]. https://www.bsg.ox.ac.uk/research/ research-projects/coronavirus-government-response-tracker. Accessed 8 Jan 2020

Passavanti, M., A. Argentieri, D.M. Barbieri, B. Lou, K. Wijayaratna, A.S.F. Mirhosseini, F. Wang, S. Naseri, et al. 2021. The psychological impact of COVID-19 and restrictive measures in the world. Journal of Affective Disorders 283: 36-51. https://doi. org/10.1016/j.jad.2021.01.020.

Pu, S., Z. Shao, M. Fang, L. Yang, R. Liu, J. Bi, and Z. Ma. 2019. Spatial distribution of the public's risk perception for air pollution: A nationwide study in China. Science of the Total Environment 655: 454-462. https://doi.org/10.1016/j.scitotenv. 2018.11.232.

Puett, R.C., J.E. Hart, J.D. Yanosky, C. Paciorek, J. Schwartz, H. Suh, F.E. Speizer, and F. Laden. 2009. Chronic fine and coarse particulate exposure, mortality, and coronary heart disease in the Nurses' Health Study. Environmental Health Perspectives 117: 1697-1701. https://doi.org/10.1289/ehp.0900572.

Reames, T.G., and M.A. Bravo. 2019. People, place and pollution: Investigating relationships between air quality perceptions, health concerns, exposure, and individual- and area-level characteristics. Environment International 122: 244-255. https://doi.org/10.1016/j.envint.2018.11.013.

Rodríguez-Urrego, D., and L. Rodríguez-Urrego. 2020. Air quality during the COVID-19: PM2.5 analysis in the 50 most polluted capital cities in the world. Environmental Pollution 266: https:// doi.org/10.1016/j.envpol.2020.115042.

Rotko, T., L. Oglesby, N. Künzli, P. Carrer, M.J. Nieuwenhuijsen, and M. Jantunen. 2002. Determinants of perceived air pollution annoyance and association between annoyance scores and air pollution (PM2.5, NO2) concentrations in the European EXPOLIS study. Atmospheric Environment 36: 4593-4602. https://doi.org/10.1016/S1352-2310(02)00465-X.

Rugani, B., and D. Caro. 2020. Impact of COVID-19 outbreak measures of lockdown on the Italian Carbon Footprint. Science of the Total Environment 737: https://doi.org/10.1016/j. scitotenv.2020.139806.

SAAQIS South African Air Quality Information System. 2020. SAAQIS South African Air Quality Information System [WWW Document]. http://saaqis.environment.gov.za/. Accessed 8 Jan 2020.

Saksena, S. 2011. Public perceptions of urban air pollution risks. Risk, Hazards, \& Crisis in Public Policy 2: 19-37. https://doi.org/10. 2202/1944-4079.1075.

SanJuan-Reyaes, S., L.M. Gómez-Oliván, and H. Islas-Flores. 2020. COVID-19 in the environment. Chemosphere 263: https://doi. org/10.1016/j.chemosphere.2020.127973.

Sarkar, P., N. Debnath, and D. Reang. 2020. Coupled humanenvironment system amid COVID-19 crisis: A conceptual model to understand the nexus. Science of the Total Environment 753: https://doi.org/10.1016/j.scitotenv.2020.141757.

Sax, L.J., S.K. Gilmartin, and A.N. Bryant. 2003. Assessing response rates and nonresponse bias in web and paper surveys. Research in Higher Education 44: 409-432.

Schusky, J. 1966. Public awareness and concern with air pollution in the st. Louis metropolitan area. Journal of the Air and Waste
Management Association 16: 72-76. https://doi.org/10.1080/ 00022470.1966 .10468444$.

Shakil, M.H., Z.H. Munim, M. Tasnia, and S. Sarowar. 2020. COVID-19 and the environment: A critical review and research agenda. Science of the Total Environment. https://doi.org/10. 1016/j.scitotenv.2020.141022.

Sharma, S., M. Zhang, G.J. Anshika, H. Zhang, and S.H. Kota. 2020. Effect of restricted emissions during COVID-19 on air quality in India. Science of the Total Environment. https://doi.org/10.1016/ j.scitotenv.2020.138878.

Shi, X., and G.P. Brasseur. 2020. The response in air quality to the reduction of Chinese economic activities during the COVID-19 outbreak. Geophysical Research Letters 47: 1-8. https://doi.org/ 10.1029/2020GL088070.

Sicard, P., A. De Marco, E. Agathokleous, Z. Feng, X. Xu, E. Paoletti, J.J.D. Rodriguez, and V. Calatayud. 2020. Amplified ozone pollution in cities during the COVID-19 lockdown. Science of the Total Environment. https://doi.org/10.1016/j.scitotenv.2020. 139542.

Siciliano, B., G. Carvalho, C.M. da Silva, and G. Arbilla. 2020a. The impact of COVID-19 partial lockdown on primary pollutant concentrations in the atmosphere of Rio de Janeiro and São Paulo megacities (Brazil). Bulletin of Environment Contamination and Toxicology 105: 2-8. https://doi.org/10.1007/s00128020-02907-9.

Siciliano, B., G. Dantas, C.M. da Silva, and G. Arbilla. 2020b. Increased ozone levels during the COVID-19 lockdown: Analysis for the city of Rio de Janeiro, Brazil. Science of the Total Environment. https://doi.org/10.1016/j.scitotenv.2020.139765.

Sillman, S., and D. He. 2002. Some theoretical results concerning O3NOx-VOC chemistry and NOx-VOC indicators. Journal of Geophysical Research: Atmospheres. https://doi.org/10.1029/ 2001JD001123.

Singh, V., S. Singh, A. Biswal, A.P. Kesarkar, S. Mor, and K. Ravindra. 2020. Diurnal and temporal changes in air pollution during COVID-19 strict lockdown over different regions of India. Environmental Pollution. https://doi.org/10.1016/j.envpol. 2020.115368.

Smith, T.W. 1984. Recalling attitudes: An analysis of retrospective questions on the 1982 GSS. Public Opinion Quarterly. 48, 639-649. https://doi.org/10.1086/268865.

Smith, W.S., J.J. Schueneman, and L.D. Zeidberg. 1964. Public reaction to air pollution in Nashville, Tennessee. Journal of the Air and Waste Management Association 14: 418-423. https:// doi.org/10.1080/00022470.1964.10468307.

Solga, H. 2001. Longitudinal surveys and the study of occupational mobility: Panel and retrospective design in comparison. Quality \& Quantity 35: 291-309. https://doi.org/10.1023/A: 1010387414959.

Sovacool, B.K., D. Furszyfer Del Rio, and S. Griffiths. 2020. Contextualizing the Covid-19 pandemic for a carbon-constrained world: Insights for sustainability transitions, energy justice, and research methodology. Energy Research \& Social Science. https://doi.org/10.1016/j.erss.2020.101701.

Srivastava, S., A. Kumar, K. Bauddh, A.S. Gautam, and S. Kumar. 2020. 21-Day Lockdown in India Dramatically Reduced Air Pollution Indices in Lucknow and New Delhi, India. The Bulletin of Environmental Contamination and Toxicology 105: 9-17. https://doi.org/10.1007/s00128-020-02895-w.

Stafoggia, M., G. Cesaroni, A. Peters, Z.J. Andersen, C. Badaloni, R. Beelen, B. Caracciolo, J. Cyrys, et al. 2014. Long-term exposure to ambient air pollution and incidence of cerebrovascular events: Results from 11 European cohorts within the ESCAPE project. Environmental Health Perspectives 122: 919-925. https://doi. org/10.1289/ehp.1307301. 
Stockemer, D., 2019. Quantitative Methods for the Social Sciences. Springer, Cham. https://doi.org/10.1007/978-3-319-99118-4.

Tong, L., K. Li, and Q. Zhou. 2014. The association between air pollutants and morbidity for diabetes and liver diseases modified by sexes, ages, and seasons in Tianjin, China. Environmental Science and Pollution Research 22: 1215-1219. https://doi.org/ 10.1007/s11356-014-3432-4.

Tversky, A., D. Kahneman. 1981. The framing of decisions and the psychology of choice. Science (80-.). 211, 453-458.

United States Environmental Protection Agency. 2020. Air Data: Air Quality Data Collected at Outdoor Monitors Across the US [WWW Document]. https://www.epa.gov/outdoor-air-qualitydata.

Venter, Z.S., K. Aunan, S. Chowdhury, and J. Lelieveld. 2020. COVID-19 lockdowns cause global air pollution declines. Proc: Proceedings of National Academy of Sciences. https://doi.org/ 10.1073/pnas.2006853117.

Wang, G., S. Cheng, W. Wei, X. Yang, X. Wang, J. Jia, J. Lang, and Z. Lv. 2017. Characteristics and emission-reduction measures evaluation of PM2.5 during the two major events APEC and Parade. Science of the Total Environment 595: 81-92. https://doi. org/10.1016/j.scitotenv.2017.03.231.

Wang, P., K. Chen, S. Zhu, Peng. Wang, and H. Zhang. 2020a. Severe air pollution events not avoided by reduced anthropogenic activities during COVID-19 outbreak. Resources, Conservation and Recycling. https://doi.org/10.1016/j.resconrec.2020.104814.

Wang, Q., and M. Su. 2020. A preliminary assessment of the impact of COVID-19 on environment-A case study of China. Science of the Total Environment. https://doi.org/10.1016/j.scitotenv. 2020.138915.

Wang, Y., Y. Yuan, Q. Wang, C.G. Liu, Q. Zhi, and J. Cao. 2020b. Changes in air quality related to the control of coronavirus in China: Implications for traffic and industrial emissions. Science of the Total Environment. https://doi.org/10.1016/j.scitotenv. 2020.139133.

WHO. 2006. WHO Air quality guidelines for particulate matter, ozone, nitrogen dioxide and sulfur dioxide. Geneva.

WHO. 2016. Ambient air pollution: A global assessment of exposure and burden of disease. Geneva.

WHO. 2020a. Coronavirus disease (COVID-19) pandemic [WWW Document]. https://www.who.int/emergencies/diseases/novelcoronavirus-2019. Accessed 8 Jan 2020.

WHO. 2020b. Coronavirus Disease (COVID-19) Dashboard [WWW Document]. https://covid19.who.int/. Accessed 8 Jan 2020.

Wilder-Smith, A., and D.O. Freedman. 2020. Isolation, quarantine, social distancing and community containment: Pivotal role for old-style public health measures in the novel coronavirus (2019nCoV) outbreak. Journal of Travel Medicine 27: 1-4. https://doi. org/10.1093/jtm/taaa020.

$\mathrm{Wu}, \mathrm{T} .2021$. The socioeconomic and environmental drivers of the COVID-19 pandemic: A review. Ambio. 50: 822-833. https:// doi.org/10.1007/s13280-020-01497-4.

Yadav, R., N. Korhale, V. Anand, A. Rathod, S. Bano, R. Shinde, R. Latha, S.K. Sahu, et al. 2020. COVID-19 lockdown and air quality of SAFAR-India metro cities. Urban Climate. https://doi. org/10.1016/j.uclim.2020.100729.

Yang, D., C. Ye, X. Wang, D. Lu, J. Xu, and H. Yang. 2018. Global distribution and evolvement of urbanization and PM2.5 (1998-2015). Atmospheric Environment 182: 171-178. https:// doi.org/10.1016/j.atmosenv.2018.03.053.

Publisher's Note Springer Nature remains neutral with regard to jurisdictional claims in published maps and institutional affiliations.

\section{AUTHOR BIOGRAPHIES}

Baowen Lou $(\varangle)$ is Doctoral Candidate at Chang'an University and visiting Researcher at Norwegian University of Science and Technology (NTNU). Her research interests mainly focus on civil sustainable infrastructures and environmentally friendly technologies.

Address: School of Highway, Chang'an University, Nan Er Huan Road (Mid-section), Xi'an 710064, Shaanxi, China.

Address: Department of Civil and Environmental Engineering, Norwegian University of Science and Technology, Høgskoleringen 7A, 7491 Trondheim, Trøndelag, Norway.

e-mail: loubaowen@chd.edu.cn; baowen.lou@ntnu.no

Diego Maria Barbieri $(\square)$ is Postdoctoral Researcher at Norwegian University of Science and Technology (NTNU). His research interests encompass infrastructure engineering and sustainable technologies applied in the built environment.

Address: Department of Civil and Environmental Engineering, Norwegian University of Science and Technology, Høgskoleringen 7A, 7491 Trondheim, Trøndelag, Norway.

e-mail: diego.barbieri@ntnu.no; diegomb271@gmail.com

Marco Passavanti is Psychologist registered with The Order of Psychologists of Emilia-Romagna. He is member of the Italian Society of Cognitive Behavioural Therapy (CBT-Italy). He currently works as freelance professional in clinical psychology and psychoeducational interventions.

Address: Italian Society of Cognitive Behavioural Therapy (CBTItaly), Mannelli St. 139, 50132 Firenze, Toscana, Italy.

e-mail:m.passavanti@campus.unimib.it

Cang Hui is Professor at Stellenbosch University and a South African Research Chair in mathematical and theoretical physical biosciences. His research focuses on investigating the structure and function of spatial biodiversity and ecological networks.

Address: Centre for Invasion Biology, Department of Mathematical Sciences, Stellenbosch University, Matieland 7602, South Africa.

Address: Biodiversity Informatics Unit, African Institute for Mathematical Sciences, Cape Town 7945, South Africa.

e-mail: chui@sun.ac.za

Akshay Gupta is Doctoral Candidate at Indian Institute of Technology Roorkee (IITR). His research interests include walkability, pedestrian, accessibility, driving behaviour, human factors and road safety.

Address: Department of Civil Engineering, Transportation Engineering Group, Indian Institute of Technology Roorkee, 321-A\&B, Roorkee, Uttarakhand 247667, India.

e-mail: akshay_g@ce.iitr.ac.in

Inge Hoff is Professor at Norwegian University of Science and Technology (NTNU). His research interests mainly include infrastructure engineering and transportation engineering.

Address: Department of Civil and Environmental Engineering, Norwegian University of Science and Technology, Høgskoleringen 7A, 7491 Trondheim, Trøndelag, Norway.

e-mail: inge.hoff@ntnu.no

Daniela Antunes Lessa is Professor at Federal University of Ouro Preto (UFOP), Associate Professor in post-graduation program at Federal University of Minas Gerais (UFMG) and a Ph.D. in geography from UFMG. Her research interests include transportation planning, urban space organization and geography of transportation, 
which includes the use of quantitative methods applied to spatial analysis.

Address: Department of Civil Engineering, Federal University of Ouro Preto, Rua Nove, Bauxita, Ouro Preto, Minas Gerais 35400-000, Brazil.

e-mail: daniela.lessa@ufop.edu.br

Gaurav Sikka is an Assistant Professor at the Department of Geography, Lalit Narayan Mithila University. His research interest includes social geography, environmental and gender issues in development-induced displacement, resettlement and rehabilitation. Address: Department of Geography, Lalit Narayan Mithila University, Darbhanga, Bihar 846004, India.

e-mail: gauravsikkageo@gmail.com

Kevin Chang is Associate Professor at the University of Idaho. His research interests include transportation safety, traffic operations, engineering education and workforce development.

Address: Department of Civil and Environmental Engineering, University of Idaho, 875 Perimeter Drive, Mailstop 1022, Moscow, ID 83844, USA.

e-mail: kchang@uidaho.edu

Kevin Fang is Assistant Professor at Sonoma State University. His research interests include micromobility, travel behaviour and the connection between transportation and land use.

Address: Department of Geography, Sonoma State University, Environment, and Planning, 1801 East Cotati Avenue, Rohnert Park, CA 94928, USA.

e-mail: fangk@sonoma.edu

Louisa Lam is Senior Lecturer at Federation University and Adjunct Senior Research Fellow at Monash University. Her research interests include public health, medicine, nursing, mental health and occupational health.

Address: School of Health, Federation University Australia, 72-100

Clyde Rd, Berwick, VIC 3806, Australia.

e-mail:1.lam@federation.edu.au

Brij Maharaj is Senior Professor at the University of KwaZuluNatal. His research interests include urban politics, migration and human rights.

Address: Department of Geography, University of KwaZulu-Natal, Howard College City, Durban 4000, KwaZulu, South Africa.

e-mail: maharajb@ukzn.ac.za

Navid Ghasemi is Postdoctoral Researcher at the University of Bologna (UNIBO). His research interests include transport infrastructure engineering, road safety and sustainable mobility.

Address: Department of Civil Chemical Environmental and Materials Engineering, University of Bologna, Viale del Risorgimento, 2, 40136 Bologna, Emilia-Romagna, Italy.

e-mail:navid.ghasemi3@unibo.it

Yaning Qiao is Associate Professor at the China University of Mining and Technology. His research interests include resilient transportation infrastructure and sustainability.

Address: School of Mechanics and Civil Engineering, China University of Mining and Technology, Daxue Road 1, Xuzhou 22116, Jiangsu, China.

e-mail: yaning.qiao@cumt.edu.cn

Solomon Adomako is Doctoral Candidate at University of Agder (UiA). His research interests include construction materials and associated technologies.
Address: Department of Engineering and Science, University of Agder, Jon Lilletuns vei 9, 4879 Grimstad, Agder, Norway.

e-mail: solomon.adomako@uia.no

Ali Foroutan Mirhosseini is Doctoral Candidate at Norwegian University of Science and Technology (NTNU). His research interests include transportation economy and project management.

Address: Department of Civil and Environmental Engineering, Norwegian University of Science and Technology, Høgskoleringen 7A, 7491 Trondheim, Trøndelag, Norway.

e-mail: ali.mirhosseini@ntnu.no

Bhaven Naik is an Associate Professor in the department of Civil Engineering at Ohio University. His research interests focus various areas of transportation systems engineering including an expertise in applying advanced statistical methods and analysis techniques to transportation-related areas.

Address: Department of Civil Engineering/Russ College of Engineering \& Technology, Ohio University, 28 W. Green Drive, Athens, OH 45701, USA.

e-mail: naik@ohio.edu

Arunabha Banerjee is Doctoral Candidate at the Indian Institute of Technology (IIT). His research interests include pedestrian behaviour modelling and safety.

Address: Department of Civil Engineering, Indian Institute of Technology Guwahati, Guwahati, Assam 781039, India.

e-mail: arunabhabanerjee77@gmail.com

Fusong Wang is Doctoral Candidate at Wuhan University of Technology. His research interests include asphalt pavement construction and associated environmental assessments.

Address: State Key Laboratory of Silicate Materials for Architectures, Wuhan University of Technology, Luoshi road 122, Wuhan 430070, Hubei, China.

e-mail:wangfs@whut.edu.cn

Andrew Tucker is Research Associate at University of Connecticut, Connecticut Transportation Safety Research Center. His research activities mainly focus on the psychological relationships between perceptions and actions.

Address: Connecticut Transportation Safety Research Center, University of Connecticut, 270 Middle Turnpike, Unit 5202 Longley Building, Storrs, CT 06269, USA.

e-mail: andrew.tucker@uconn.edu

Zhuangzhuang Liu is Associate Professor at Chang'an University. His main research interests include civil infrastructure management, travel behaviour analysis and systems reliability.

Address: School of Highway, Chang'an University, Nan Er Huan Road (Mid-section), Xi' an 710064, Shaanxi, China.

e-mail: zzliu@chd.edu.cn

Kasun Wijayaratna is Lecturer at the University of Technology Sydney. His research interests include civil infrastructure management, travel behaviour analysis and systems reliability.

Address: School of Civil and Environmental Engineering, University of Technology Sydney, 81, Broadway, Ultimo, NSW 2007, Australia. e-mail: Kasun.Wijayaratna@uts.edu.au

Sahra Naseri is Psychologist working at Bam University of Medical Sciences. Her research interests cover the relationships between psychological health and well-being applied to multiple contexts. Address: School of Medicine, Bam University of Medical Sciences, Bam, 76615-336 Kerman, Iran. e-mail: sahra.naseri1989@gmail.com 
Lei Yu is Doctoral Candidate at Sun Yat-sen University. His research interests include engineering mechanics, geotechnical engineering and offshore structures.

Address: School of Civil Engineering, Sun Yat-Sen University, Xingang Xi Road 135, Guangzhou 510275, Guangdong, China. e-mail: yulei26@mail2.sysu.edu.cn

Hao Chen is Doctoral Candidate at Norwegian University of Science and Technology (NTNU). His research interests mainly include characterising the resilient properties of asphalt materials and innovative road pavement design.

Address: Department of Civil and Environmental Engineering, Norwegian University of Science and Technology, Høgskoleringen 7A, 7491 Trondheim, Trøndelag, Norway.

e-mail: hao.chen@ntnu.no

Benan Shu is Doctor at Foshan Transportation Science and Technology Co., Ltd. His research interests include ultrahigh performance fibre reinforced concrete and sustainable technologies applied in asphalt pavement.

Address: Foshan Transportation Science and Technology Co. Ltd., Kuiqi Second Road 18, Foshan 528000, Guangdong, China.

e-mail: shuba@whut.edu.cn

Shubham Goswami is Research Scholar at Indian Institute of Science Bangalore (IISc Bangalore). His research interests include water resources management and groundwater hydrology.

Address: Department of Civil Engineering, Indian Institute of Science Bangalore, C V Raman Avenue, Bangalore, Karnataka 560012, India. e-mail: gshubham@iisc.ac.in
Prince Peprah is Doctoral Candidate at the University of New South Wales. His research interests include environmental health and public health.

Address: Department of Social Policy Research Centre, University of New South Wales, John Goodsell Building, Kensington, Sydney, NSW 2052, Australia.

e-mail: princepeprah15@gmail.com

Amir Hessami is Assistant Professor at Texas A\&M UniversityKingsville. His research interests include infrastructure asset management and sustainability of built infrastructure.

Address: Department of Civil and Architectural Engineering, Texas A\&M University - , Kingsville, 917 W. Ave B, Kingsville, TX 78363, USA.

e-mail: hessami_amir@tamu.edu

Montasir Abbas is Associate Professor in the transportation infrastructure and systems engineering program at Virginia Tech, he developed and implemented several systems in the areas of transportation modelling, management, and control.

Address: Department of Civil and Environmental Engineering, Virginia Tech, 301-D3 Patton Hall, Blacksburg, VA 24061, USA.

e-mail: abbas@vt.edu

Nithin Agarwal is the Director of the Florida Technology Transfer (T2) Center and manages the Transportation Safety Center at the University of Florida Transportation Institute. His main research interests include transportation safety, traffic engineering, traffic signal systems and emerging technologies.

Address: Department of Civil \& Coastal Engineering, University of Florida, 2100 NE Waldo Rd., Sta 106, Gainesville, FL 32609, USA. e-mail: nithin.agarwal@ufl.edu 